\title{
EL MATRIMONIO \\ DE GUILLERMA DE \\ CASTELLVELL
}

\section{Blanca Garí}

Durante casi dos siglos las prácticas matrimoniales de la nobleza feudal catalana orientaron sus esfuerzos hacia la perpetuación familiar, tanto como hacia la renovación de las alianzas entre los linajes. En función de ello se concibieron repetidas veces matrimonios hipergámicos; sea por repudio, divorcio, o viudedad, los jefes de los linajes de la aristocracia de los siglos XI y XII contrajeron sucesivas alizanas matrimoniales. Ellas, sus mujeres, las viudas, las repudiadas, las divorciadas, fueron entregadas una y otra vez a nuevos linajes, renovando los pactos, perpetuando las alianzas. Sólo lentamente una concepción diversa sobre el matrimonio fue penetrando en la sociedad de la época, provocando tensiones, enfrentamientos, pero imponiéndose progresivamente sobre al menos algunas de las prácticas que habían gobernado las estrategias matrimoniales de los linajes feudales. Era la visión de los hombres de la Iglesia, la de los monjes, luego la de los clérigos; quería instruir, rectificar, reconducir la moral laica y, por tanto, el matrimonio. Desde el último cuarto del siglo XII la repercusión del discurso eclesiástico sobre la nobleza laica se percibe con mayor claridad, la moral que predicaba, adaptándose, ha triunfado hacia el año $1200^{1}$.

En este contexto debe situarse la figura de Guillerma, esposa de

1 Ver al respecto GeORGes DUBY Medieval Marriage. Two Models from Twelftb-Century France, Baltimore-London 1978 y Le Chevalier, la Femme et le Prètre. Le mariage dans la France Féodale, Hachette, Paris 1981. 
Guillem Ramon de Montcada, vizconde de Bearn, y de Aimeric, vizconde de Narbona, ella misma, señora de Castellvell. Su padre, Guillem Ramon III de Castellvell, uno de los más importantes magnates de la Cataluña de Ramon Berenguer IV y del rey trovador, había hecho testamento en $1176^{2}$. Se trata de un documento importante: en él se perciben los trazos de lo que va a suponer una mutación profunda en el linaje de Castellvell. Pero lo que me interesa destacar aquí es únicamente la forma en que establece sus legados: deja todo el señorío, compuesto por tres segmentos bien diferenciados (las tierras del Penedès, las del Llobregat, y las de la zona de reconquista en Tarragona), a su hijo Guillem, - llamado posteriormente Albert-, excepto el castillo de Voltrera el cual, según la costumbre establecida a lo largo del último siglo, será ostentado por el segundogénito Gombau en feudo del primogénito; a sus dos hijas, - piezas fundamentales en los acontecimientos que se van a suceder en los próximos años- deja a Guillerma 1000 morabetinos sobre el castillo de Mataró, y a Alamanda la encomienda a su hermano para que la case abonoríficamente»; establece como orden de sucesión en primer lugar a Guillem, y en segundo a Gombau; pero si ambos murieran sin descendencia sus honores deberán dividirse entre sus dos hijas, Guillerma a la que deja todo su honor excepto lo que posee en la $\mathrm{Ri}$ bera - por tanto los sectores del Penedès y el Llobregat- y Alamanda a la que le corresponderían las tierras de la Ribera, es decir, la zona de Tarragona. Esta decisión va a ser de fundamental importancia en el desarrollo de la organización territorial del s. XIII. Convertidas ambas en herederas, Guillerma pasará a formar parte del linaje de Montcada/Bearn orientando hacia ese vizcondado las tierras de la Cataluña vieja, y Alamanda penetrará por matrimonio en el linaje de Sant Martí (enlazando en posteriores generaciones con el de Entenza), inclinándose su sector hacia las tierras de reconquista valenciana. Un análisis de la organización territorial en el siglo XIII del que fue el señorío de Castellvell debe comenzar sin duda en este testamento.

Pero en 1176 es Guillem/Albert quien hereda el señorío. Des-

2 Archivo de la Corona de Aragón (A.C.A.), Monacales, Gran Priorato S. Juan de Jerusalén, armario 28, n: 272, extraviado; transcripción en J. Pasqual, manuscrito 729 de la Biblioteca de Cataluña; y en J. Miret i SANS. Les cases dels Templers y Hospitalers en Catalunya. Aplech de noves y documents bistorichs, Barcelona, 1910, pp. 232-234. 
de esta fecha, las líneas directrices que habían gobernado la estructura interna del linaje de Castellvell parecen transformarse. En el campo de las estraregias matrimoniales, el cambio puede ser observado en dos planos diferentes: en primer lugar, Albert de Castellvell no contrae matrimonio. En la abundante documentación conservada sobre él no aparece casado ni una sola vez, y tampoco existe indicio alguno de que tuviera descendencia. Los motivos de este hecho, insólito en un heredero primogénito y cabeza de linaje, escapan a cualquier interpretación posible, pero la constatación del hecho en sí y la observación del modo peculiar como se resuelve su herencia nos indican el grado del cambio que se ha operado ${ }^{3}$. En segundo lugar, las dos mujeres del linaje no renuevan los pactos matrimoniales de otras generaciones: ni son entregadas al linaje vizcondal ${ }^{4}$, ni consolidan los lazos feudales con los linajes de vasallos 5 . Sus matrimonios inician una nueva etapa de relaciones entre los linajes de la aristocracia catalana, tendentes a ampliar la esfera de las posibilidades de elección y alejar el grado de consanguinidad. Alamanda contrac matrimonio con Guillem de Sant Martî ${ }^{6}$, primogénito de uno de los más prestigiosos linajes de la sociedad feudal catalana y, desde entonces, adoptando el nombre de Subirats (castillo patrimonial de Sant Martí que su esposo le otorga en esponsalicio), penetra plenamente en el seno de ese linaje al que aporta sus tierras cuando años más tarde se con-

3 Gombau, el segundo hijo de Guillem Ramon III de Castellvell, debió mori poco después del testamento de su padre, pues no reaparece en la documentación: el celibato del primogénito, Albert, conllevó a su muerte la carencia de heredero, y la división prevista por el testamento de su padre entre las dos hijas se Hevó a cabo hacia 1205.

4 Por lo que sabemos sobre el linaje de Castellvell, a lo largo del s. XII y durante tres generaciones entregaron una de sus mujeres al linaje vizcondal. En esta generación se rompe tal alianza. Ver J. E. Ruiz DOMENEC eSystème de parenté et théorie de l'alliance dans la societé catalane (env. 1000-cnv. 1240)», Revue Historique, 262, 2, 1980.

5 Asimismo nos son bien conocidas, a través de la documentación, las alianzas entre los Castellvell y sus feudatarios en Castellvell de la Marca, los Banyeres, iniciadas con el matrimonio de Guilia con Pere Mir de Banyeres a la vez que le era entregada la custodia del castillo a finales del s. XI; A.C.A., Cancillería, ExtraInventario, carpera 363, documento 3.449.

6 Hijo de Anglesa y de Guillem de Sant Martí; es decir, hijo del segundo matrimonio de este Guillem que contrae alianzas sucesivamente con Beatriz de Montcada, divorciada de Guillem Ramon de Montcada, con Anglesa, y con Guilia de Banyeres. 
vierte en heredera. Menos sencillo es el análisis de la trayectoria seguida por la mayor de las hermanas, que aparece en la documentación sucesivamente como Guillerma de Montcada (1189-1202), Guillerma vizcondesa de Narbona (1202-1208), y Guillerma de Castellvell (1205-1225). Estos cambios y osilaciones en la forma de denominación han confundido en ocasiones a la historiografía, preguntándose sobre la posibilidad de que se tratase de diferentes personas 7 , o más generalmente intentando interpretar las causas ${ }^{8}$. Es evidente que el principal problema surge a raiz del matrimonio de Guillerma con Aimeric de Narbona, en vida de su primer marido Guillem Ramon de Montcada, y por tanto en la legitimidad de esta segunda alianza. Sin embargo, si se introduce el problema en el contexto que he descrito, se podrá observar cômo la práctica hipergámica de la mayor de las hijas de Guillem Ramon III de Castellvell $\rightarrow$ acorde aún con la tradición laico/aristoctática, aunque enfrentada a las nuevas directrices de la moral cclesiástica tanto como al nuevo papel que Guillerma debía asumir en la organización de su sociedad-fracasó en la primera década del s. XIII.

Guillerma debió contraer matrimonio hacia 1176, dado que su padre concreta la dote que le corresponde ya en esa fecha, pero la primera mención documental que tenemos de ella, posterior al testamento, es de $1189^{9}$ cuando, por consejo y voluntad de su marido Guillem Ramon de Montcada, llega a un acuerdo con su hermano Albert sobre la herencia de su madre Balasquita. En este documento Guillerma misma recibe el apellido toponímico de su esposo asimilándose por el nombre, punto de referencia del lina-

7 J. Miret i Sans, aLa Casa de Montcada en el vizcondado de Bearns, en Boletin de la Real Academia de Buenas Letras, 1901-2, ya planteaba el problema y aportaba pruebas documentales más que suficientes para demostrar que se trataba de una misma persona, hija de Guillem de Castellvell y Balasquita de Vilademuls y hermana de Albert de Castellvell; y sin embargo, en la p. 239 entre sus conclusiones sigue considerando que el doble matrimonio de Guillerma constituye \&....un grave obstaculo para admitir que las dos Gullermas de Castellvell sean una sola personas y se pregunta *... ¿sería acaso preferible suponer que Doก̃a Balasquita tuvo dos hijas del mismo nombre, llamadas ambas Guillerma, casada una con el señor de Montcada y otra con el de Narbona?

8 Por ejemplo, F. DURAN Y CANAMERAS, «El señorio de Castellvells, en Boletín de la Real Sociedad Arqueológica Tarragona, 1927; y B. PEDEMONTE Y FAl GUERA. Notes per a la bistorria de la Baronia de Castellvell de Rosanes, Barcelona, 1929 Pp. 136 y ss.

9 A.C.A., Cancillería Alfonso I, 514. 
je, al grupo familiar de su marido (... ego Guilelma de Monte Catano... $)$. Es éste un fenómeno insólito hasta esta ćpoca ${ }^{10}$ y más sorprendente aún en una ocasión como ésta en la que actúa en una cuestión concerniente a su propio linaje de origen. A partir de esta fecha, y en los años que se suceden hasta final de siglo encontramos a Guillerma con frecuencia en la documentación de su esposo, rodeada, junto a él, del entorno familiar y feudal de los Montcada (Centellas, Clasquerí, Sentmenat...) ${ }^{11}$. Sin embargo, en 1194 se produce un hecho que ha conmovido a la historiografía, dando lugar desde antiguo a múltiples versiones e incluso leyendas $^{12}$ se trata del asesinato del avunculus de Guillerma, Berenguer de Vilademuls, arzobispo de Tarragona, llevado a cabo por Guillem Ramon de Montcada, su esposo. Naturalmente éste ha sido el principal argumento sobre el que han girado las interpretaciones de la separación de Guillerma y de su intento de contraer nuevo matrimonio, la distancia cronológica que separa estos dos hechos me inclina a pensar en la necesidad de una mayor cautela y de cierta precisión al valorarlos. El primer hecho, el asesinato del arzobispo por el esposo de su sobrina, se encuentra recubierto por una leyenda que oculta sus verdaderos motivos. El asesinato de un pariente tan significativo en las relaciones familiares que habían gobernado los destinos de los feudales,. al menos hasta pocas décadas antes, es sin duda escandaloso; ahora bien, si este avunculus resulta ser el mismo arzobispo de Tarragona, el hecho

10 A lo largo de los siglos XI y XII la mujer no recibe prácticamente nunca el apellido toponímico. En el linaje de Castellvell conocemos un sólo caso: Sicardis, esposa de Bonfill Guillem de Castellvell, recibe en una sola ocasión (1084) el nombre de siciardis femina de Castro Vetulis, justificado por el hecho de que su esposo ha muerto sin descendencia y ella actúa en ese documento como eventual cabeza de linaje en un asunto que concierne estrictamente al linaje de Castell. vell, Archivo de la Caredral de Barcelona, Diversorum C(b), n: 290.

11 A.C.A., Cancillería Alfonso I, n: 549; y Cartulario de Sant Cugat, fol. 12. doc. 18, ed. por J. Rius Serra, El Cartulario de Sant Cugat del Vallés, C.I.S.C., Barcelona, 1949, doc, n: 1188.

12 Por ejemplo Blanch, Arcbiepiscopologo Tarnaconense (archivo Capitular de la catedral de Tarragona) cap. XX; P. BERnat Mauot. Libre Blancb, Biblio. teca Provincial de Tarragona, cap. X al XV: P. RiBERA, Milicia Mercedaria, Pp. 606 y ss, ; y E. Morera, Tarragona Cristiana, 1897. La mayorí2 de estas versiones historiográficas las recoge M. COL. I Alentorn en su libro La Legenda de Guillem Ramon de Montcada, Barcelona, 1958, pp. 36 y ss, para pasar después a describir las versiones legendarias. 
adquiere, para la sociedad de finales del s. XII, una dimensión extraordinaria.

Son pocos, en cambio, los documentos contemporáneos conservados en relación a este hecho. El primero es el testamento sacramental del propio arzobispo Berenguer de Vilademuls, dictado de palabra en el momento de ser herido ( $\ldots$...quod dominus archiepiscopus iacebat vulneratus in terra...v ${ }^{13}$ en presencia de su capeIlán Guillem Climent, y de su notario Ferrer. El segundo es la bula de Celestino III por la que excomulga a Guillem Ramon y a sus cómplices «...quod filius iniquitatis Guillelmus Raimundi obstinata et pertinaci audacia perpetrare praesumpsit non (...) patrem suum et dominum, et cuius neptem in uxorem babebat, videlicet bonae et piae memoria Berengarium Terraconensem Archiepiscopus sceleratas manus inmitere et ipsum crudeli gladior mortaliter trucidare.... ${ }^{14}$. Tal excomunión fue redactada en el cuarto año del pontificado de Celestino, cinco meses después del homicidio, y en ella se describe con detalle la forma en que fue llevado a cabo. El tercer y último documento referente a estos hechos que nos ha llegado es una absolución carente de fecha. Su datación ha sido muy discutida oscilando entre el 1198 y $1219^{15}$ en él se absuelve, en nombre del Pontifice, a Guillem Ramoní de Montcada bajo la penitencia de entrar en Tarragona descalzo, con los brazos extendidos, una cuerda al cuello, la camisa cruzada, y hacerse azotar en una iglesia de las afueras, para luego dirigirse a la catedral a rogar el perdón al arzobispo; posteriormente debía dirigirse a Tierra Santa ${ }^{16}$. La riqueza del lenguaje gestual de la penitencia aparece con toda claridad en este texto.

Con estos tres documentos finaliza todo cuanto sabemos realmente acerca del homicidio. Ricos en expresiones, callan, sin embargo, los posibles motivos. Al relacionar este asesinato con la separación de Guillerma y Guillem Ramon, se ha sostenido que probablemente los motivos que llevaron a su esposo a cometer el homicidio eran de orden familiar, y que la separación o anulación

13 Documento publicado por Villanueva en Viaje Literario a las Iglesias de España, vol. XIX, apéndice n? XI. pp. 309.

14 Ibid., n: XI, Pp. 305.

15 Morera y B. Pedemonte y Falguera la sitúan en 1198; F. Durán y Cañameras en 1209; y M. Coll y Alentorn, basándose en la coincidencia de los episcopados, entre 1213 y 1219.

16 Villanueva, op. cit., no XXXII, pp. 304. 
matrimonial se produjo a raíz del asesinato ${ }^{17}$. Sin embargo, yo creo que se trata de cuestiones que deben disociarse claramente: en primer lugar porque, como ya he dicho, la distancia cronológica entre ellos así lo indica; en segundo lugar porque tal separación coincide prácticamente con el nuevo matrimonio de Guillerma; en tercero porque no parece que el primer matrimonio fuera disuelto en ningún momento por la Iglesia.

Tras el asesinato de su tío materno, Guillerma vuelve a aparecer con el nombre de Guillerma de Montcada, no sólo en asuntos del linaje de su esposo (como el cambio de Vacarisses por 700 morabetinos, llevado a cabo entre Alfonso II y domna Guillelma de Monte Catano en 1195$)^{18}$ sino también en los de su linaje de origen: en 1197 Albert de Castellvell, por ejemplo, obliga a su hermana, domna Guillelma de Monte Catano, el castillo de Falset por los 800 morabetinos que aún le debía en el de Mataró . ....per vocem patris nostri Guillelmi de Castro Veteri... ${ }^{19}$. Guillerma se considera, pues en estas fechas posteriores al asesinato, e incluso hasta 1202, en el que vuelve a aparecer como Guillerma de Montcada ${ }^{20}$, plenamente miembro del linaje de su esposo.

Por ello considero que los motivos del asesinato del arzobispo de Tarragona, Berenguer de Vilademuls, deben buscarse más bien en el acontecer político de estos años, en el significado fundamental adquirido por el linaje de Vilademuls, y en especial por el arzobispo, en la corte del rey trovador, y en los conflictos que se dirimían entre diferentes sectores de la nobleza. No en vano los Vilademuls son el signo más claro del cambio que se ha operado entre el personal político del monarca, y no en vano Berenguer pertenece a la segunda generación de una familia ascendida fuertemente al calor del poder condal en época de Ramon Berenguer IV, y que posteriormente con Alfonso II llegan a los más altos puestos de la administración real. Berenguer es el más cercano consejero del Rey, y no deja de ser significativa la coincidencia de su muerte con la revuelta de los magnates pirenaicos contra el monarca y el obispo de Urgell, así como el matiz que incluye la bula de Celstino III excomulgando no sólo a Guillermo Ramón de Mont-

17 Por ejemplo B. Pedemonte y Falguera, op, cit., p. 127-128.

18 A.C.A., Cancillería Alfonso I, n? 705.

19 A.C.A., Cancillería Pedro I, n: 33.

20 A.C.A. Cancillería Pedro I, n? 127. 
cada sino también a complices eius. Por todo ello creo poder sostener que el homicidio perpetrado por su esposo y la consecuente excomunión, tuvo escasa o nula influencia en la separación de Guillerma.

En el mismo año 1202 (en el que en un documento del mes de marzo aún figura como Guillerma de Montcada) aparece como vizcondesa de Narbona, junto con su nuevo esposo el vizconde Aimeric $^{21}$. El doble matrimonio de Guillerma no está en absoluto en desacuerdo con las prácticas matrimoniales que pueden observarse en la aristocracia catalana de los s. XI y XII, e incluso en el propio linaje de Castellvell ${ }^{22}$. La mujer, como bien donado, puede pasar a formar parte de otro grupo familiar, puede ser nuevamente donada, o también arrebatada, puede ser repudiada y tomada por otro linaje. Los motivos de la actitud hipergámica adoptada por Guillerma deben encuadrarse sin duda en esta estructura. La documentación jurídica tan sólo constata el hecho, limitándose a reproducir la nueva situación social de Guillerma como vizcondesa de Narbona. Sin embargo, sabemos que la práctica de la hipergamia se llevó a cabo en la sociedad feudal por divorcio, repudio o viudedad, y Guillerma no había enviudado. Por otro lado, hacia el año 1200 ha cambiado profundamente la repercusión de la moral eclesiástica sobre el matrimonio de los laicos. Por lo que sabemos de su postura combativa contra la costumbre laicoaristocrática de multiplicar sus alianzas, podemos suponer que este segundo matrimonio en vida de su primer esposo jamás fue aceptado ni legitimado por la Iglesia, que continuó considerándola esposa de Guillem Ramon de Montcada. Ello resulta tanto más seguro cuanto que pocos años después (1208) se separa definitivamente del vizconde de Narbona, y reaparece acompañada casi siempre de su hijo Guillem de Montcada, bajo el nombre de Guillerma de Castellvell.

En realidad, cuando esto sucede Guillerma hace dos años que

21 A.C.A., Cancillería Pedro I, n: 143.

22 Entre la aristocracia catalana existen ejemplos múltiples de matrimonios hipergámicos como los del citado Guillem de Sant Martí con Anglesa, Beatriz, y Guilia, o los de la propia Beatriz con Guillem Ramon de Montcada, del que se divorcia, y con Guillem de Sant Martí. Dentro del propio linaje de Castellvell te. nemos la seguridad de que Guillem Ramon I contrajo dos alianzas matrimonia. les, con Santxa y Ermensenda, y Guillem Ramon II probablemente otras dos de las que sólo conocemos el nombre de la primera, Mahalta. 
se ha convertido, al fallecer su hermano Albert, en heredera del antiguo señorío de Castellvell, es decir, de los segmentos del Penedès y de Rosanes. Desde noviembre de 1205 acompaña su título de vizcondesa de Narbona del nombre de Guillerma de Castellvell ${ }^{23}$. De igual forma aparece en una donación a Sant $\mathrm{Cu}$ gat en abril del siguiente año «...ego Guillelma de Castro Veteri. Dei Gratia vicecomitisse Narbone.... ${ }^{24}$ y en los diversos acuerdos con su principal feudataria Guilia de Banyeres en 1207 y $1208^{25}$. Finalmente, a partir del mes de agosto de 1208 no vuelve a figurar como vizcondesa de Narbona, sino únicamente como señora de Castellvell, rodeada del entorno del linaje compuesto por los linajes vasallos (además de Banyeres, Castellbisbal, Castellvell de la Marca.... $)^{26}$. Esta transformación en la denominación es importante, pues de ella resulta que Guillerma no recibe el apellido toponímico de su linaje de origen a consecuencia - como se ha llegado a insinuar - de su doble separación, y a falta de otra forma de denominación. Muy al contrario, Guillerma, todavía vizcondesa de Narbona, asume la herencia peculiar que estableció Guillem Ramon III de Castellvell en 1176. Muertos sus dos hermanos célibes, el señorío se divide, y ella se convierte, no ya en la heredera a través de la cual y con la cual se entregara el señorío al futuro cabeza de linaje, su esposo, sino en verdadera señora de Castellvell. La continuidad de su herencia exige la presencia de su hijo legítimo junto al que aparecerá constantemente a partir de ahora.

Paralelamente, reforzando la hipótesis de la ilegitimidad de este segundo matrimonio de Guillerma, a la vez que abundando en la idea de la tendencia a la hipergamia en contra de las prescripciones eclesiásticas, puede observarse el primer testamento de Guillem Ramon de Montcada redactado en el año 1215, probablemente poco después de la absolución papal ${ }^{27}$. En él se constata, por un lado, que Guillem vuelve a considerar a Guillerma de Castellvell como su esposa dado que en el documento la denomina $\approx u x x^{28}$, y por otro, que existe una segunda mujer, en este ca-

${ }^{23}$ A.C.A. Cancillería Pedro $I, n^{\circ} 218$.

24 A.C.A., Cartulario de Sant Cugat, fol. 213, doc. 661, ed. J. Rius Serra, op. cit, doc. $\mathrm{n}: 1.262$.

is A.C.A., Cancillería Pedro 1, n: 260; ibid. n: 281; ibid. n? 282; ibídem p. 283.

26 A.C.A., Cancilleria Pedro 1, n: 296; íbid. n? 342; ibid. n: 367.

27 Archivo Histórico Nacional Clero, Santes Creus, carpeta 2.776, doc, 14.

28 a...et quia predictum castrum de sponsalicio est uxoris mee Guillelme....". 
so clarísimamente ilegítima (Navarra), de la que Guillem Ramon tiene varios hijos e hijas (Almurs, Navarra, Berenguer, Ramon Guillem y Bernat), a los que llama en el documento afilios meos naturales». Se trata, por tanto, de una práctica hipergámica ilegítima pero abiertamente confesada, dado que mujer e hijos no sólo aparecen en el testamento, sino que se les lega dinero, y se les encomienda al heredero legítimo. De esta manera se reconoce el papel de indudable importancia de los hijos bastardos en el entorno del futuro jefe de linaje al que deben permanecer unidos: a...rogans affectione paterna liberalitatem suam ut Dei amore et mei et fraterna dilectionis vinculo eos diligat, benefaciat eis in terris, et in honoribus, et in pecuniis....; ; excluidos normalmente del sistema de herencia, los hijos bastardos reciben en este testamento la promesa de ser beneficiados por el heredero, no sólo en dinero sino también en honores y en tierras - signo indudable del rango e importancia que ostentan en la cercanía del cabeza de linaje.

Sin embargo, observando el conjunto de estas estrategias matrimoniales, - a pesar de la indudable importancia del segundo matrimonio de Guillerma y de la figura de Navarra como kcompañera» de Guillem Ramon- debo reconocer que, a comienzos del siglo XIII, la que va a determinar el porvenir de las alianzas a lo largo del siglo, es la establecida entre el linaje de Montcada y el de Castellvell. Guillem de Montcada, hijo de Guillerma y Guillem Ramon, será el heredero legítimo tanto del señotío materno como del paterno: señor de Montcada, vizconde de Bearn, y señor de Castellvell, es él el único que penetrará en el juego de alianzas matrimoniales trabado a lo largo del siglo XIII, mientras que la hija de Guillerma y Aimeric de Narbona, y los hijos e hijas de Guillem Ramon y Navarra restan al margen.

En conclusión, hacia el año 1200 las prácticas hipergámicas de la aristocracia feudal catalana persisten. Sin embargo, tienden cada vez más, a operarse al margen de la legitimidad eclesiástica y del propio sistema de alianzas. El primer matrimonio de Guillerma no fue nunca, en mi opinión, anulado por la Iglesia; el segundo, producto del único motivo posible, el repudio, nunca fue legitimado. Pero además va a ser el fruto del primer matrimonio el que importe para el futuro sistema de alianzas y para el propio sistema de herencia. En este sentido, puede decirse que ha triunfado la penetración de la moral eclesiástica en los esquemas mentales de la sociedad de finales del s. XII, pues ha sustraido a las prácti- 
cas hipergámicas de su razón de ser principal, de la fuente de la que emanaban: asegurar la perpetuación del linaje y renovar las alianzas. 